\title{
Estimation of Economic Costs of Flood Impacts of Typhoon "Crising" in Kabacan, North Cotabato, Philippines
}

\author{
Jennet R. Mag-aso ${ }^{1, ~ *, ~ R i c o ~ C . ~ A n c o g ~}{ }^{2}$, Enrique P. Pacardo ${ }^{2}$, Corazon L. Rapera ${ }^{3}$ \\ ${ }^{1}$ Department of Agricultural Economics, University of Southern Mindanao, Kabacan, Philippines \\ ${ }^{2}$ School of Environmental Science and Management, University of the Philippines, Los Banos, Philippines \\ ${ }^{3}$ Department of Agricultural Economics, University of the Philippines, Los Banos, Philippines
}

Email address:

jjrioboca@yahoo.com(J.R. Mag-aso),jrmagaso@up.edu.ph(J. R. Mag-aso)

${ }^{*}$ Corresponding author

\section{To cite this article:}

Jennet R. Mag-aso, Rico C. Ancog, Enrique P. Pacardo, Corazon L. Rapera. Estimation of Economic Costs of Flood Impacts of Typhoon "Crising" in Kabacan, North Cotabato, Philippines. International Journal of Agricultural Economics. Vol. 3, No. 2, 2018 , pp. 31-36. doi: $10.11648 /$ j.ijae.20180302.12

Received: March 7, 2018; Accepted: April 18, 2018; Published: May 15, 2018

\begin{abstract}
Kabacan town in Mindanao, Southern Philippines, which is situated on the flood plain of Cotabato Province, has been heavily affected on flooding in the recent years. Flooding on February 2013 brought about by typhoon "Crising" had worsened as compared to previous flooding events in the area. This flood event has caused heavy damage to agriculture, and economy of the town. The economic impacts of February 2013 flooding was evaluated and monetized. Valuation techniques comprised of clean-up costs method, crop damage and loss of foregone income was used to estimate the economic costs of flooding. Economic costs comprised of loss of income from rice production, loss of income from other source, clean-up costs and government spending were reached up to Php20, 451,247.49. Findings of the study will be beneficial to the Local Government of Kabacan, particularly to the Municipal Disaster Risk Reduction and Management, Municipal Agriculture Office and to the Climate Change Commission as flooding is one of the major concerns of Climate Change.
\end{abstract}

Keywords: Flooding, Economic Costs, Flood Impacts, Valuation

\section{Introduction}

Floods resulting from excessive rainfall within a short duration of time and the consequent high river discharge can damage crops, infrastructure and other property [13]. Foster [6] categorized impacts of floods into two types: the short term and long-term impacts. Short term impacts include: death, injury, loss of infrastructure, damage to property and business, damage to crops and diseases. Long term impacts include: damaged infrastructure, houses, uninsured losses, loss of trade and industry, public perception of place and high costs of insurance. Local communities may experience flood events with devastating damages and economic losses [16].

A case study conducted in Bangladesh concluded that much of the country's budget was used for the recovery after floods thereby affecting the economy of the country [6]. The impacts can affect national economies in the long term [17]. Benson [3] revealed that the low- lying agriculturally developed and economically productive lands in Bicol, Central Luzon, Central Samar, Northern Samar and Eastern Mindanao regions are frequently affected by extreme flooding events. The flood plains of Agno, Agusan, Bicol, Pampanga, Panay, Cagayan, and Cotabato are highly susceptible to severe flooding [1].

Flood caused damage to agriculture on which Kabacan's rural economy heavily depends on. The frequency of flooding in the area due to natural occurrence and man-made enhancement has been increasing over the years, resulting to damage to crop particularly on rice production, losses of income and additional government expenditures. The estimation of economic loss due to floods were considered necessary to justified the need to implement flood damage mitigation program including the need to explore other potential flood response strategies, flood insurance, flood protection projects among others.

The study aimed to: 
1. Determine the economic impacts of flooding in terms of:

a. Loss of income from rice production

b. Loss of income from other sources

c. Clean-up costs

d. Government expenditure due to flood event

2. Monetize the value of economic impacts of February 2013 flooding in Kabacan.

\section{Materials and Methods}

The survey was conducted in Kabacan, North Cotabato, the Rice Granary of the Province of North Cotabato. The town has a total land area of 44,809 ha, $51 \%$ of which is devoted to agriculture while more than 7,000 ha is planted with irrigated rice land.

A total of 320 households in flood-prone areas were selected using stratified simple random sampling. The primary data was gathered through personal interview with the respondents using the interview schedule while the secondary data was acquired at the different offices of the Local Government Unit of Kabacan.

The data was analysed using the Statistical Program for Social Sciences (SPSS). The loss of income from rice production was analyzed using replacement cost method and market price method while the loss of income from other source was analysed through loss of foregone income. Cleanup costs method was used to analyse the costs of removing the debris and sediments at the house and rice field. Replacement costs method considers the cost incurred by replacing the losses with artificial substitute (Dixon et al., 1997). Market price method is demonstrated through the price or a good or service purchased in the market (Kahn, 1998).

The value of economic impacts of flooding are presented as follows:

\subsection{Loss in Farm Income}

The estimated loss in farm income was computed as follows:

$$
\left.\left.E c d_{i}=\sum_{i=1}^{320}\left(\left(\left(H w o_{i}-C p_{i}\right) P_{i}\right)-\left(H w_{i}-C p_{i}\right) P_{i}\right)\right)\right)
$$

where:

Ecd= estimated value of crop damage

Hwo $=$ expected average harvest with-out floods

$\mathrm{Cp}=$ costs of production

$\mathrm{Hw}=$ actual harvest with flood event

$\mathrm{P}=$ price

\subsection{Loss in Income from Other Sources}

The estimated loss in income from other sources was computed as follows:

$$
L i_{i}=\sum_{i=1}^{320}\left(\left(N d_{i} x W_{i}\right)\right)
$$

where:

$\mathrm{Li}=$ Loss in income from other sources

$\mathrm{Nd}=$ number of days affected

$\mathrm{W}=$ wage per day

\subsection{Clean-up Costs}

The costs of removing debris and sediments either at the farm houses and rice fields were computed as follows:

$$
L c_{i}=\sum_{i=1}^{320}\left(\left(W n_{i} \times N d_{i} \times W w_{i}\right)\right)
$$

where:

$\mathrm{Lc}=$ Labor costs

$\mathrm{Wn}=$ No. of workers hired

$\mathrm{Nd}=$ No. of days working

$\mathrm{Ww}=$ Wage of worker a day

\subsection{Government Expenditure}

The value of the government expenditure in flooding events in Kabacan was based on the secondary data of the expenses incurred by the different government agencies. These data were collected from the Municipal Social Welfare and Development Office (MSWDO.

\section{Results and Discussions}

\section{Economic Value of Flood Impacts}

Loss of Farm Income.

The overall total farm size that was covered in the study was 465.46 ha with an average 1.455-1.5 ha per respondent. The table 1 below shows the estimated loss of farm income due to flood event in the area.

Table 1. Total loss of farm income due to flood event.

\begin{tabular}{ll}
\hline VARIABLES & AMOUNT, PHP \\
\hline Gross farm income without flood & $39,092,498.50$ \\
Less: Total costs & $7,010,695.30$ \\
Estimated net income without flood & $32,081,803.20$ \\
Actual farm income with flood & $20,256,695.70$ \\
Less: Estimated costs & $7,010,695.30$ \\
Estimated net income with flood & $13,245,957.40$ \\
Total loss of farm income & $18,835,845.80$ \\
\hline
\end{tabular}

The total gross farm income from harvested rice paddy without flood event was at Php 39,092,498.50. On the other hand, due to flood experienced by the famers in their area, the actual farm income from rice production went down to Php 20,256,695.70. The total costs of producing rice for the total land area covered in the study were amounted to Php $7,010,695.30$. Therefore, the total loss of farm income due to flood event was reached up to Php 18,835,845.80.

Meanwhile, the average gross income per respondent with- 
out flood amounted to Php 83,986.00 and the average costs per farmer per cropping season was Php 15,061.86. Moreover, the decrease in the average gross income of affected farmers was due to the unexpected timing of the flood waters that hit their area. Flood damage to rice paddy depends on whether that stage of growth of the rice is vulnerable or not. The stages in which the rice plant is most vulnerable to flooding are the reproductive, ripening and maturity/harvestable stages.

The flood event hit the area at the time when rice paddy was already ready to be harvested, with the farmers sustaining heavy losses as the grains of the rice paddy were flushed away by the flood waters. The farmers usually harvest even if the rice paddy is not fully matured to prevent untoward events from totally damage their standing crop. In the event that they failed to harvest before the flood events, by practice, they still harvest even after the floods to save what they can from their rice paddy. In terms of pricing on the said crop, buyers classify it into wet and dry. The price difference of around $\mathrm{Php} 1.00 / \mathrm{kg}$ in which is the dry rice paddy is much higher than wet.

The table 2 shows the different costs incurred in farming rice. The costs involved in producing rice paddy were the following: land preparation, seeds, payment for the planters, fertilizers, pesticides and payment for the harvesters and machine used for harvesting.

Table 2. Total costs of rice production.

\begin{tabular}{ll}
\hline PRACTICES & COSTS, PHP \\
\hline Land preparation & $706,463.00$ \\
Seeds & $659,420.00$ \\
Planting & $412,641.00$ \\
Fertilizer & $751,796.00$ \\
Pesticides & $676,095.00$ \\
Harvesting & $3,804,280.30$ \\
Total & $7,010,695.30$ \\
\hline
\end{tabular}

Loss of Income from Other Sources

Respondents were accepting and doing part-time jobs/works aside from maintaining and taking care of their own farms. They accepted seasonal works from other farms and other sources that could give them an extra income to help provide for their daily living expenses. This could be an additional income for them while waiting for the harvest of the rice paddy which takes more or less four months depending on the variety of seeds they used. The jobs/works that respondent took on included weeding, spraying of pesticides and applying fertilizers.

The study supported the recommendation of Haque, et al. [7], in exploring other employment opportunities aside from agriculture sector. This is to lessen the vulnerability of the farmers in the advent of flood hazard.

The work that farmers usually engaged in work done for a day or for a minimum of one day and the payments received by the farmers from these jobs ranged from Php100 to Php200/ha/day. Other source of income that respondents engaged in was driving tricycles. The income received by the respondents from this extra work ranged from Php100-
Php250/day. This kind of work/job was done when the respondents were not busy in their respective farms. Some farmers also did carpentry, house cleaning, grass cutting and other jobs that could give them income.

The study revealed that during the flood events, around 61 respondents were affected by the flood event in which they can no longer do and perform the job from the other sources. The number of days that the respondents cannot perform their job due to flood event ranged from 1-7 days. The lowest income that the respondent received each day was Php 100 and the highest income received per day of absent was Php 727.27. The total loss of income from other sources among the 61 respondents affected were amounted to Php 62,306.69.

Clean-up Costs

During flood events, respondents just stayed in their respective areas and observed the behaviour of flood waters (i.e, water level) and the weather conditions. Some of the respondents secured their material possessions to prevent damage if the worst case scenario happens.

The flood waters did not immediately subside and continued to submerge the farm houses and rice fields for 1-2 days. Table 3 shows the total clean-up costs in removing the debris and sediments after the flood event.

When the flood water subsided, sediments were left inside and outside the vicinity of farm houses as well as at the rice field. Debris was also found after the floods. To clean the house, family members helped each other to do the cleaning activities. There were also some respondents who hired an average of three individuals to do the cleaning activities. The minimum payment for the hired individuals was Php 50 and the maximum of Php 150/ day with free meal and snack. The cleaning activities were completed in one day. Thus, the total cost of cleaning and removing debris and sediments at the house vicinity amounted to Php86, 190(Table 3).

Table 3. Total clean-up costs at the house vicinity and at the rice field.

\begin{tabular}{ll}
\hline ACTIVITIES & CLEAN-UP COSTS, PHP \\
\hline $\begin{array}{l}\text { Cleaning \& removing of debris and } \\
\text { sediments at the house vicinity }\end{array}$ & $86,190.00$ \\
$\begin{array}{l}\text { Cleaning \& removing of debris and } \\
\text { sediments at the rice field }\end{array}$ & $102,465.00$ \\
Total & $188,655.00$ \\
\hline
\end{tabular}

With regards to the prices of houses located inside the floodplain, the study of Beltran et al. [2] revealed that there's an increase in the discount for houses from $2.9 \%$ to $6.9 \%$. Their findings change the perception of the land owners towards flood risk. The prices of properties vary on the location of the area especially on the floodplain area which command a lower price as compared to area which are not flooded.

At the flooded rice field, farmers were also doing clean-up activities. They remove debris and sediments and reconstructed the "pilapil" (small dam) because these were destroyed by the currents of flood waters. Some respondents hired workers to do the job that was usually completed at 1-3 days with an average of two individuals. The average wage per individual was Php105/ day. Thus, the total costs of 
cleaning activities at the rice field amounted to Php102, 465(Table3). Therefore, the total cost for cleaning activities at the farm houses and at the rice fields reached to Php. 188,655 (Table 3).

Government Expenditures to Address Flooding Events in Kabacan

During the February 2013 flood event in the area, different government agencies spent huge amounts of money for relief operations in response to the affected families. Among the government agencies that extended help by giving relief goods were the Department of Welfare and Development Office Field Office Region XII (DSWD FO XII), Department of Agriculture Regional Field Unit XII (DA RFU XII), Province of North Cotabato, Kabacan Water District (KWD) and the LGU Kabacan. The expenditures of the different agencies are presented in Table 4.

Table 4. Government expenditures to address the February 2013 flooding in Kabacan.

\begin{tabular}{ll}
\hline GOVERNMENT AGENCY & ESTIMATED EXPENDITURES, PHP \\
\hline DSWD FO XII & $402,000.00$ \\
DA Region XII & $165,000.00$ \\
Kabacan Water District & $22,920.00$ \\
(KWD) & $103,518.00$ \\
Province of North Cotabato & $671,002.00$ \\
LGU Kabacan & $1,364,440.00$ \\
\hline
\end{tabular}

The DSWD FO XII extended its assistance to the affected families by sending 2000 family packs of relief goods with each pack containing 3 kilos rice, 4 cans sardines and 3 pieces noodles. The estimated amount spent by the said agency for the relief goods amounted to Php402, 000.

On the other hand, DA RFU XII spent around Php165, 000 for their assistance to the families affected by floods in Kabacan. Cotabato province spent about Php103, 518 as response to the flood events in Kabacan. The province provided 729 family packs of relief goods to the affected families. Each pack has an estimated amount of Php142. Kabacan Water District was another agency that extended help to the flood victims in the area. The agency spent around Php22, 920 giving 120 packs of relief goods and 240 bottled of water to those affected by the floods.

Lastly, the municipality spent a big amount of money to respond to the flood events in the area. It provided relief goods to the affected families. The estimated amount spent by the municipality due to the flooding amounted to Php 671,001 . Moreover, the municipality also spends big amounts of money for the relief operations every time there are flood events in the area (MDRRMO).

Therefore, the total government expenditures during the flood events reached to $\mathrm{Php} 1,364,440.00$. This is not supposedly limited to giving relief goods during the events of flooding, but government might provide an early warning system and advise on mitigation and technical support on emergency response, training as well as early dissemination of warning but government support to community activities significantly influence community's adaptation in mitigating the impact of flooding [10]. These could help the government minimize the impact of flooding.

Disaster risk management, an important component of which is a community-based early warning system, is important if communities are to prepare their populace and try to mitigate the adverse effects of weather events. These efforts should also be closely connected to the local economic and social interests of the respective communities [9].

\section{Total Economic Costs of Flood Impacts}

Table 5. Total economic costs of flood impacts.

\begin{tabular}{ll}
\hline ECONOMIC COSTS & TOTAL, PHP \\
\hline Loss of Farm Income & $18,835,845.80$ \\
Loss of Income from other source & $62,306.69$ \\
Clean-up Costs & $188,655.00$ \\
Government Expenditure & $1,364,440.00$ \\
Total & $20,451,247.49$ \\
\hline
\end{tabular}

The study revealed that the economic costs of flood impacts were reached to Php20, 451,247.49 (Table 5).

This included the loss of farm income, loss of income from other sources, clean-up costs and government expenditure to address the flooding effects in the area. Loss of farm income was the biggest portion of the total economic costs of flood impacts of which around Php18, 835,845.80. Winter et al. [18], considered three categories in measuring impacts of the flooding event. They measured impacts in terms of its direct economic impacts, direct consequential economic impacts and indirect consequential economic impacts. They found out that the direct costs of flooding were small, but the direct consequential costs amounted to $£ 3,200 \mathrm{k}$ which is much greater than impacts of landslide. Therefore, flood events have higher impacts as compared with any other natural hazard but of course depending also with the magnitude and intensity of the impacts.

The second largest economic costs of flood impacts were the government expenses due to flood event. Around Php1, 364,440 of the total economic value of flood impacts was the expenditure of the government as response to flood event. These amounts were used for the relief operations for the affected families and communities.

A study conducted by Svetlana, et al. [15] in Europe revealed that around 55 billion EUR was the economic losses of flood events from 1999- 2009. Social and economic impacts of flooding vary considerably.

Further, the loss of rice production affects the rice supply of the town and the province as a whole. The recurrent flood event affects the local economy of the town.

\section{Conclusions}

Loss of farm income from rice production was the highest economic costs of flood damage. It was amounted to Php18, $835,845.80$.

The loss of farm income from rice production among the respondents was due to the unexpected timing of flood waters that hit the area. Rice paddy was vulnerable to flood 
during the reproductive, ripening and maturity stage. Therefore, strategic planning among the farmers together with the National Irrigation Administration (NIA) so that farmers can adjust and change the time of planting and the NIA can also change their schedule on the release of irrigation water to avoid huge farm harvest/ income losses.

The amounts spent by the government to address problems caused by the flood event could have probably been better used to formulate projects that prevent flooding, which in the long term can be more useful and helpful to reduce the impacts of flooding in the area. Thus, recurrent government expenditure for relief operations can be avoided. Moreover, the possible flood protection projects to be implemented might help prevent loss of income on the part of the affected communities.

This can also be useful to avoid additional expenses on the part of the affected families in removing the sediments and debris in their house and in the rice field after the flood event.

In planning any intervention to be made by the policy maker and with regards to policy related to flood problems, it needs to have a community participation [14].

\section{Recommendations}

On the flood impacts to crop, development of flood tolerant variety of rice that can adapt to soil, water, temperature and other environmental and physical conditions of the area is recommended. In addition, detailed information on the physical and environmental conditions on the floodprone barangays will be needed because it serves as baseline information for the scientists who are interested to develop a new variety of seeds applicable to the situation of the area.

On protection of the rice field and the entire community affected, development of major creeks and canals is recommended. This is to ensure the continuous flows of water and to avoid clogging of waterways that induced flooding.

Meanwhile, government should develop a comprehensive plan on flood risk reduction and management and enhance/strengthen the preparedness system rather than focus on the response. Some government policies towards mitigating floods fails to include the traditional knowledge and indigenous practices as it serves as the important consideration in crafting and implementing policies to reduce the socio-economic impacts and vulnerabilities of the people in the advent of flooding [4].

Moreover, in planning for the agricultural land-use of the area, the role of government policy is important in considering the possible effect of natural disaster like flooding on crop production [11].

Further, due to the extreme impacts of flooding in the area which is very costly to the farmers, the affected communities, as well as to the government, this should be instructive in terms of investments in addressing the flooding problem. Instead of spending money for the relief operation, the government should plan investments and seek projects that have long term benefits that could minimize and lessen the impacts of flooding.

There were several interventions and projects that were made to address the problem of flooding. Samela et al. [12] developed a web platform that promote global collaboration and co-operative geomorphic flood mapping of the entire globe. Their studies induced awareness and it serves a tool for the policy maker globally as flooding is one of the costliest disaster worldwide.

\section{Acknowledgements}

This study was supported by Department of AgricultureBureau of Agricultural Research. The authors would like to thank the local government unit and the local people (especially the rice farmers) of Kabacan, North Cotabato, Philippines.

\section{References}

[1] ASIAN Development Bank (ADB). 1994. Climate change in Asia: Philippines country report: regional study on global environmental issues. Manila.

[2] BELTRAN, A., MADDISON, D., ELLIOT, R. JR., 2018. Is Flood Risk Capitalised Into Property Values?. Ecological Economics 146 (2018) 668-685.

[3] BENSON, C. 1997. The economic impact of natural disasters in the Philippines. (Working paper 99). London: Overseas Development Institute.

[4] DEWANN, T., 2015. Societal Impacts and Vulnerability to Flood in Bangladesh and Nepal. Weather and Climate Extremes 7 (2015) 36-45.

[5] DIXON, et. al. 1997. Economic analysis of environmental impacts. Earth scan Publications, London, UK (1997).

[6] FOSTER, J., 2010, Impacts of floods, AS Geography. Available at www.slideshare.net

[7] HAQUE, A., JAHAN, S., 2015. Impacts of Flood Disaster in Bangladesh: A Multi-Sector Regional Analysis. International Journal of Disaster Risk Reduction 13 (2015) 266-275.

[8] KAHN, J. 1998. The economic approach to environmental and natural resources. The Dryden Press. Orlando, FL (1998) pp. 88-106 as cited by Rebecca, et.al. 2003. A review of ecosystem valuation technique.

[9] LARSEN, M. C., 2008. Rainfall-triggered landslides, anthropogenic hazards, and mitigation strategies. Advances in Geosciences 14, 147-153.

[10] LIANG, Y., JIANG, C., MA, L., LIU, L., CHEN, W., LIU, L., 2017. Government Support, Social Capital and Adaptation to Urban Flooding by Residents in the Pearl River Delta Area, China. Habitat International 59 (2017) 21-31.

[11] PANICHVEJSUTI, T., KUWORNU, JKM., SHIAVAKOTI, G., GRUNBUHEK, C., 2018. Small Farmers' Crop Combinations under different Land Tenure Systems in Thailand: The Role of flood and Government Policy. Land use Policy 72 (2018) 129-137. 
[12] SAMELA, C., ALBANO, R., SOLE, A., MANFREDA, S., 2018. A GIS Tool for Cost- Effective Delineation of Flood Prone Areas. Computer and Environmental Journal, 2018.

[13] SANYAL, J., and LU, X., 2004. Application to Remote Sensing in Flood Management with Spatial Reference to Monsoon Asia: A Review. Natural Hazards 33: 283- 301, 2004.

[14] SHORT GIANOTTI, A., WARNER, B., MILMAN, A., 2018. Flood Concerns and Impacts on Rural Land Owners: An Empirical Study of the Deerfield Watershed, MA (USA). Environmental Science and Policy 79 (2018) 94-102.

[15] SVETlanA, D., RADOVAN, D., JAN, D., 2015. The Economic Impact of Floods and their Importance in Different Regions of the World with Emphasis on Europe. Business
Economics and Management 2015 Conference, BEM2015. Procedia Economics and Finance 34(2015) 649-655.

[16] VOZINAKI, A-E. K., KOURGIALAS, N. N., KARATZAS, G. P., 2012. Estimating flood inundation and the consequent economic losses in the Koiliaris River Basin in Crete, Greece, Global NEST Journal, Vol 14, No 3, pp 284-293, 2012.

[17] WILLIAMS, W., 2004, Magnitude and Frequency and the Flood Hazard. Available at www.slideshare.net

[18] WINTER, M., SHEARER, B., PALMER, D., PEELING, D., HARMER, C., SHARPE, J., 2016. The Economic Impact of Landslide and Floods on Road Network. Advances in Transportation Geotechnics 3. The $3^{\text {rd }}$ International Conference on Transportation Geotechnics (ICTG 2016). Procedia Engineering, Volume 143, 2016, Pages 1425-1434. 